\title{
DETERMINANTS OF INTRAUTERINE FOETAL DEATH
}

\author{
Parinita Anil Khot ${ }^{1}$, Yamini Patil2, Sanjay Patil 3 , N. S. Kshirsagar 4
}

${ }_{13}^{\text {rd }}$ Year Resident, Department of Obstetrics and Gynaecology, Krishna Institute of Medical Sciences, Karad. ${ }^{2}$ Associate Professor, Department of Obstetrics and Gynaecology, Krishna Institute of Medical Sciences, Karad. 3 Professor, Department of Obstetrics and Gynaecology, Krishna Institute of Medical Sciences, Karad. 4 Professor and Head of Unit, Department of Obstetrics and Gynaecology, Krishna Institute of Medical Sciences, Karad.

ABSTRACT
BACKGROUND
IUFD is defined as death prior to complete expulsion or extraction from mother of products of conception after the age of viability.
It is important to identify specific determinants of foetal death to determine the risk of recurrence and prevention of same.

\section{OBJECTIVES}

This study was conducted to analyse the maternal and foetal causes leading to intrauterine foetal death as well as the placental and cord factors associated with the same. The management of patients with intrauterine foetal death was also studied.

\section{METHODS}

We conducted a hospital based prospective observational study at Krishna Institute of Medical Sciences, Karad, India, between June 2013 and June 2015. We included all pregnant patients with singleton IUFD of greater than 28 weeks or foetal weight 1000 gm or above; 141 cases of IUFD were studied. The patients were counselled for autopsy after the delivery and the foetus along with the placenta was sent for histopathological examination to the Pathology Dept. at KIMS.

\section{RESULTS}

There were 141 cases of singleton IUFD and the incidence of IUFD was 18.6 per 1000 births; $65 \%$ of patients were unbooked cases. Peak incidence was seen in primiparous patients (54.6\%) in the age group of 21-25 years (58.9\%) and gestational age group of 37-40 weeks. Majority of the patients delivered vaginally (85.9\%). Maternal hypertensive disorders (32.6\%) and abruptio placentae $(13.4 \%)$ were the most common associated factors with foetal death. There was no factor determined in $14.1 \%$ of patients.

\section{CONCLUSION}

Most of the risk factors associated with IUFD can be prevented with regular antenatal checkups, timely admission and early referral to a tertiary care centre.

\section{KEYWORDS}

Intrauterine Death, Foetal Autopsy, Pre-Eclampsia.

HOW TO CITE THIS ARTICLE: Khot PA, Patil Y, Patil S, et al. Determinants of intrauterine foetal death. J. Evolution Med. Dent. Sci. 2016;5(33):1832-1835, DOI: 10.14260/jemds/2016/431

\section{INTRODUCTION}

Intrauterine foetal death is a heart breaking and tragic event in the field of obstetrics. According to WHO, IUFD is defined as death prior to complete expulsion or extraction from mother of products of conception after the age of viability $(28$ weeks according to Indian references and according to American College of Obstetricians and Gynaecologists, ACOG 22 weeks).1,2

The perinatal mortality rate in India has declined from $182 / 1000$ births in year 1930 to 28/1000 births in $2012 .^{3}$

Antepartum foetal death occurs 10 times more frequently than sudden infant death. Once a couple faces a foetal demise, there is always a concern of its recurrence risks.

Financial or Other, Competing Interest: None.

Submission 05-03-2016, Peer Review 31-03-2016,

Acceptance 06-04-2016, Published 25-04-2016.

Corresponding Author:

Dr. Parinita Anil Khot,

Takshila, 31/B,

Plat No. 35,

M. C. Road, Andheri (E),

Mumbai-03.

E-mail: parinita.khot@gmail.com

DOI: $10.14260 /$ jemds $/ 2016 / 431$
Foetal loss is a sensitive indicator of maternal care during antenatal period. In the developing countries, the bulk of intrauterine deaths are intrapartum and attributed commonly to the avoidable factors. In contrast, stillbirth in developed countries is largely ante-partum with no apparent cause. ${ }^{4}$ It is thus important to identify specific determinants of foetal death to determine the risk of recurrence and prevention of same. Illiteracy, poor socio-economic condition and social status of women and misbelieves are important contributory factors responsible for higher foetal mortality rates as all these factors prevent women to go to the hospital for regular ANC check-ups.

Many foetal deaths can be attributed to factors such as cord accident, foetal growth restriction, congenital anomalies, maternal hypertensive disorders, diabetes and placental abruption. ${ }^{5} \mathrm{~A}$ foetal autopsy can provide an explanation for the death and reveal a specific disorder. ${ }^{6}$ Although the couple may be hesitant for giving consent for autopsy, they should be counselled in the right way, making them understand that autopsy will help in finding a specific cause of death and also to prevent the associated risk factors in subsequent pregnancies.

Some maternal factors like pre-eclampsia and diabetes leading to foetal losses can be prevented with strict follow ups. 


\section{METHODS}

Krishna Hospital, Krishna Institute of Medical Sciences, Karad, conducts around 4950 deliveries per year. Out of 9850 deliveries in the study period between June 2013 and May 2015, there were 141 cases of singleton intrauterine foetal deaths above the gestational age of 28 weeks or weight of foetus greater than $1000 \mathrm{gm}$. Cases with multiple pregnancy and foetal deaths diagnosed before $28^{\text {th }}$ of gestation were excluded from the study. Intrapartum deaths were not included in the study.

A detailed history of above mentioned patients was noted along with past pregnancy outcomes. Details about antenatal check-ups in present pregnancies, any medical illnesses, infections, anaemia, pregnancy-induced hypertension, gestational diabetes is noted. A thorough clinical examination of the patients was done. The patient was subjected to routine blood tests and special tests like BT/CT/PT, TFTS, TORCH complex in indicated cases. Labour was induced with PGE2 gel instillation or Foley's catheter insertion after assessing the Bishop's score. Mode of delivery and the birth weights of the foetuses were noted. The foetuses were examined for any gross morphological abnormalities and the placentae were sent for histopathology examination. The foetuses after delivery were sent for autopsy with due consent to the Department of Pathology at KIMS, Karad. In our study, 27 patients gave consent for autopsy.

\section{RESULTS}

The total number of deliveries during the study period were 9850 giving incidence of IUFD as 14.3 per 1000 deliveries. As shown in Table 1, maximum incidence of IUFD was found to be in the age group of $21-30$ years (81.5\%).

\begin{tabular}{|c|c|c|c|}
\hline Sl. No. & Age of Mother & Total & \% \\
\hline 1 & $<20$ & 18 & 12.8 \\
\hline 2 & $21-30$ & 115 & 81.5 \\
\hline 3 & $31-35$ & 6 & 4.3 \\
\hline 4 & $36-40$ & 2 & 1.4 \\
\hline \multicolumn{3}{|c|}{ Table 1: Age of Mother and IUFD } \\
\hline \multicolumn{3}{|c|}{}
\end{tabular}

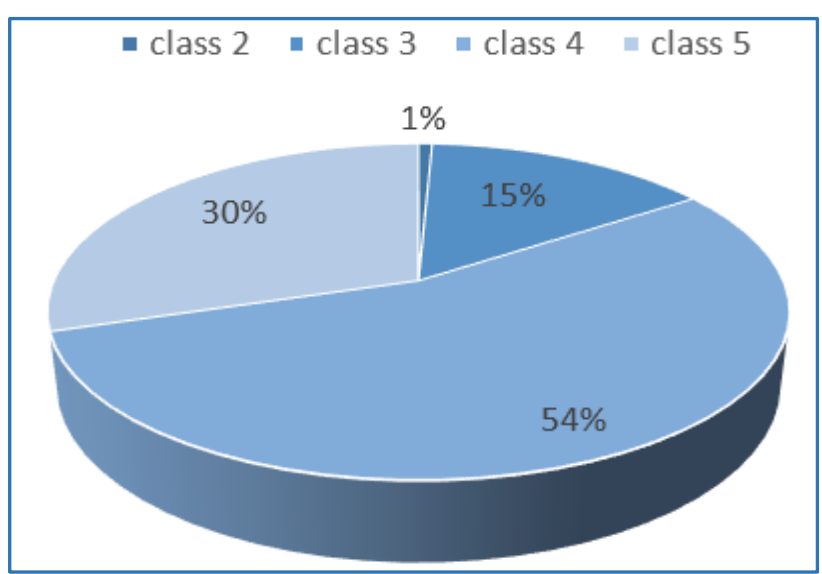

Graph 1: Socioeconomic Status and IUD

As shown in Graph 1, the incidence of IUFD had an inverse relationship with the socio-economic class. Table No. 2 , shows that most of the women were primiparous $(54.6 \%)$. The incidence of IUFD was higher among unbooked cases
(65\%) Graph 2. Maximum number of IUFD were in the gestational age of 37-40 (34\%) weeks, while preterm births collectively amounted to $62 \%$ of cases. The higher incidence of IUD was found in low birth weight foetuses weighing 10002500 grams (65.2\%). As given in Table No. 3 out of $85 \%$ patients who delivered vaginally in 52 patients, labour had to be induced with PGE2 gel; while in 14\% patients were posted for LSCS, the most common reason being Grade 3 abruption.

\begin{tabular}{|c|c|c|}
\hline $\begin{array}{c}\text { Parity } \\
\text { Status }\end{array}$ & $\begin{array}{c}\text { No. of } \\
\text { Cases }\end{array}$ & $\begin{array}{c}\text { \% of } \\
\text { Cases }\end{array}$ \\
\hline Primi & 77 & 54.6 \\
\hline Multi & 62 & 43.9 \\
\hline Grand multi & 2 & 1.5 \\
\hline Total Table 2: Parity and IUFD \\
\hline \multicolumn{2}{|c|}{} \\
\hline
\end{tabular}

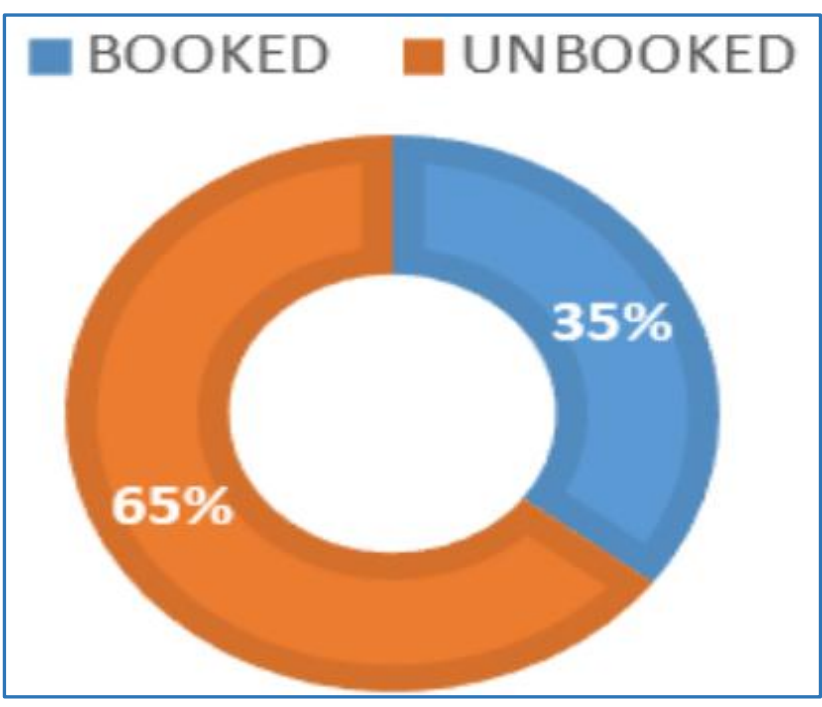

Graph 2: IUFD and Antenatal Care

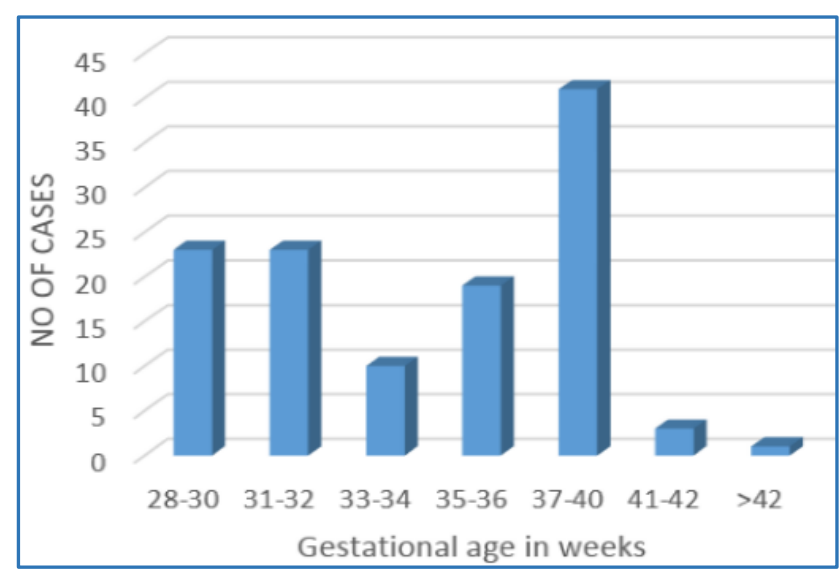

Graph 3: Gestational Age Distribution

\begin{tabular}{|c|c|}
\hline $\begin{array}{c}\text { Vaginal } \\
\text { (Spontaneous) } \mathbf{n = 1 2 1}\end{array}$ & $\begin{array}{c}\text { Vaginal } \\
\text { (Induced) } \mathbf{n}=\mathbf{1 2 1}\end{array}$ \\
\hline 41 & 80 \\
\hline LSCS & 20 \\
\hline Table 3: Mode of Delivery and IUFD \\
\hline
\end{tabular}




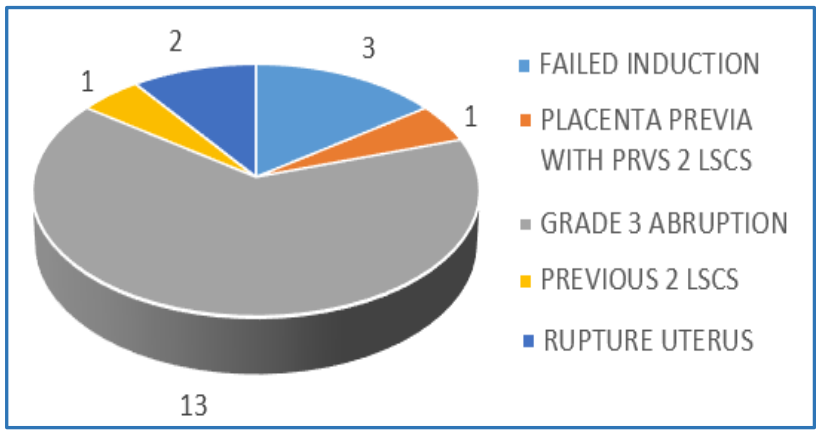

Graph 4: Indications of LSCS in Stillbirths

As shown in Table No. 3, out of 141 patients 121 patients had a vaginal delivery, of which 80 patients had to be induced labour and rest 41 patients went into spontaneous labour. The rest 20 patients underwent lower segment caesarean section for various indications as given above in the graph.

Table no. 4 shows that maternal hypertensive disorders were the most common maternal factor associated with foetal death $(32.6 \%)$. In $14.1 \%$ patient's foetal death could not be explained. The HPR reports were consistent with changes in $\mathrm{PIH}$ in $32 \%$ patients and was unremarkable in $24 \%$ patients. Out of the study groups, only 27 patients gave consent for autopsy. Foetal asphyxia was seen in 9 cases. There was meconium aspiration and bilateral pulmonary hypoplasia in 4 cases each.

\begin{tabular}{|c|c|c|c|}
\hline $\begin{array}{l}\text { Sl. } \\
\text { No. }\end{array}$ & Factor & $\begin{array}{c}\text { Booked } \\
\text { Cases }\end{array}$ & $\begin{array}{c}\text { Unbooked } \\
\text { Cases }\end{array}$ \\
\hline 1 & Abruption & 10 & 9 \\
\hline 2 & Anhydramnios & 1 & 7 \\
\hline 3 & $\begin{array}{l}\text { Congenital } \\
\text { anomaly }\end{array}$ & - & 4 \\
\hline 4 & Pre-eclampsia & 15 & 27 \\
\hline 5 & Eclampsia & - & 4 \\
\hline 6 & Anaemia & 2 & 5 \\
\hline 7 & Post maturity & - & 2 \\
\hline 8 & Cord prolapse & 1 & 1 \\
\hline 9 & IUGR & 5 & 9 \\
\hline 10 & Diabetes & 1 & 3 \\
\hline 11 & Placenta Previa & - & 1 \\
\hline 12 & PROM $>48$ hrs. & 2 & 3 \\
\hline 13 & Unexplained & 8 & 12 \\
\hline 14 & Ruptured uterus & 1 & 1 \\
\hline 15 & $\begin{array}{c}\text { Meconium } \\
\text { stained liquor }\end{array}$ & 4 & 1 \\
\hline 16 & TORCH infection & - & 2 \\
\hline & Total & 50 & 91 \\
\hline \multicolumn{4}{|c|}{ Table 4: Causes of IUFD } \\
\hline
\end{tabular}

\begin{tabular}{|c|c|}
\hline Reports & No. of Cases \\
\hline $\begin{array}{c}\text { Increased syncytial knots, } \\
\text { perivillous fibrin deposition }\end{array}$ & 45 \\
\hline Old infarction & 6 \\
\hline Chorioamnionitis & 6 \\
\hline Fresh infarct & 14 \\
\hline Intervillous haemorrhage & 18 \\
\hline
\end{tabular}

\begin{tabular}{|c|c|}
\hline Calcification & 10 \\
\hline Chronic villitis & 1 \\
\hline Acute villitis & 4 \\
\hline Retroplacental clot & 1 \\
\hline Placental hypoxia & 1 \\
\hline Immature hydropic villi & 1 \\
\hline Unremarkable & 34 \\
\hline Total & $\mathbf{1 4 1}$ \\
\hline Table 5: Histopathology Reports of Placenta \\
\hline
\end{tabular}

\begin{tabular}{|c|c|}
\hline Findings on Autopsy $\mathbf{n}=\mathbf{2 7}\}$ & No. of Cases \\
\hline B/L pulmonary hypoplasia & 4 \\
\hline Anencephaly & 1 \\
\hline Foetal asphyxia & 9 \\
\hline Pulmonary haemorrhage & 3 \\
\hline Meconium aspiration & 4 \\
\hline Features of TORCH infection & 2 \\
\hline Congenital malformation (Potter's) & 1 \\
\hline Amniotic fluid aspiration & 1 \\
\hline B/L bronchopneumonia & 2 \\
\hline \multicolumn{2}{|c|}{ Table 6: Autopsy Reports } \\
\hline
\end{tabular}

\section{DISCUSSION}

The IUFD rate continues to be high despite the advances in foetomaternal medicine. In a study conducted by Arun Nayak et al. ${ }^{7}$ in the year '93 at Nair Hospital, Bombay, the IUFD rate was 23.4 per 1000 while in studies conducted by Vaishali $\mathrm{N}$ et al. ${ }^{8}$ in 2002 and Lucy D et al. ${ }^{9}$ in 2001 incidence was 35.2 per thousand and 46.3 per thousand respectively.

Increased maternal age was not found to be a significant factor in IUFD in the present study. This can be related to the fact that Indian women complete their family at an early age. Similar higher incidence was found in age group of 21-30 years in studies done by Nayak et al (72\%) and Lucy D et al (66.6\%). In majority of the studies higher incidence was seen in unbooked or referred cases. In studies done by Kumari et al ${ }^{10}$ and Vaishali $\mathrm{N}$ et al the incidence was as high as $81.5 \%$ and $84.9 \%$ respectively.

In our study, maternal hypertensive disorder had a strong association with IUFD $32.6 \%$. This is similar to the study done by Kumari C et al (30\%) and Lucy D et al (32.8\%). Vaginal delivery should be aimed at unless there is a specific indication. In our study $85.9 \%$ delivered vaginally, in studies done by Kumari $\mathrm{C}$ et al and Vaishali $\mathrm{N}$ et al the percentage of patients that delivered vaginally was $89.4 \%$ and $73.1 \%$ respectively. Behind the preventable causes, the main cause of IUFD is the inadequate visits by the ANC patient to the doctor. In registered cases, the causes were late registration and failure to realise the significance of absent or decreased foetal movements, defaulted follow-up and non-compliance of doctor's advice and treatment were the other factors.

Placental histopathology and autopsy both contribute significantly to understanding the cause of IUFD. In our study, placental histopathology confirmed the diagnosis of the majority of the cases, while foetal autopsy provided additional diagnosis in $19.1 \%$ patients. Saller et al showed that autopsy added to the diagnosis in $44.7 \%$ cases. In a similar study done by Faye Peterson ${ }^{11}$ foetal histopathological diagnosis contributed to the pre-existing diagnosis in $51 \%$ women. The lower figure in our study is due to the non-compliance of the patient and the relatives to give consent. 


\section{CONCLUSION}

To conclude IUFD is a bitter calamity, prevention is therefore the hallmark. The antenatal foetal deaths can be minimized with regular ANC check-ups and timely admissions.

The most common cause associated with IUFD in present study was maternal hypertensive disorder, abruptio placentae and unexplained factors.

Early detection of pre-eclampsia by regular ANCs and its treatment can reduce its complications including IUD and abruption placenta in a few cases, thereby further reducing the stillbirth rate.

Death of a foetus due to congenital anomaly and death due to cord accidents cannot be totally prevented. All other factors can be prevented from causing IUD by proper care during pregnancy and undertaking induction of labour at an optimum time.

Timely admission of the patients can reduce the stillbirth rate. The factors which prevent the timely admission to a centre where facilities are available include unavailability of transport facilities and also financial constraints. Education of the patient to avail obstetric care, proper planning of midwives visits to pregnant women, more frequent check-ups for high risk pregnancies and timely referral to tertiary centre will minimize foetal wastage.

\section{REFERENCES}

1. Donald I. Prolonged pregnancy and IUFD in practical obstetric problems, Wolter Kluwer, 2014; $7^{\text {th }}$ edition:435.
2. Kochenour N. Management of foetal demise. Clin Obstet and Gynaecol 1987;30(2):322-30.

3. Park J. Preventive medicine in obstetrics, paediatrics and geriatrics in text book of preventive and social medicine, banaridas bhanot, 2015;23rd edn:562-3.

4. Archibong EI, Sobande AA, Asindi AA. Antenatal intrauterine foetal death; a prospective study in a tertiary hospital in western South Arabia. J Obstet Gynaecol 2003;23(2):170-3.

5. Huang DY, Usher RH, Kramer MS, et al. Determinants of unexplained antepartum foetal deaths. J Obstet Gynaecol 2000;95(2):215-21.

6. Saller DN, Lesser KB, Harrel U, et al. The clinical utility of the perinatal autopsy. JAMA 1995;273(8):663-5.

7. Nayak AH, Dalai AR. A review of stillbirths. J Obstet Gynaecol India 1993;43:225-9.

8. Korde Nayak, Vaishali N, Gaikwad Pradeep R. Causes of stillbirth. J Obstet Gynaecol India 2008;58(4):314-8.

9. Das Lucy, Satapathy Umakant, Panda Niharika. Perinatal mortality in a referral hospital of Orissa-a 10 year review. J Obstet Gynaaecol India 2005;55(6):517-20.

10. Kumari C, Kadam NN, Kshirsagar A, et al. Intrauterine foetal death: a prospective study. J Obstet Gynaecol India 2001;51(5):94-7.

11. Faye-Peterson OM, Guinn DA, Wenstrom KD. Value of perinatal autopsy. Obstet Gynaecol 1999;94(6):915-20. 